\title{
Influence of strength parameters of soil on the slope stability
}

\author{
Bin Bin $X U^{1, a}$ and Wei $S I^{2}$ \\ ${ }^{1}$ Tianjin Port Engineering Institution Ltd. of CCCC.; Key Lab. of Geotechnical Engineering of Tianjin; Key Lab. of Geotechnical \\ Engineering, Ministry of Communication, Tianjin 300222, China \\ 2 Tianjin Port Engineering Institution Ltd. of CCCC.; Tianjin 300222, China
}

\begin{abstract}
The stability analysis of uniform clay and sand slope is carried out using traditional limit equilibrium method and strength reduction method. In order to evaluate the influence of strength parameters including friction angle and cohesive strength, the errors among Fellenius's method, Bishop's method and strength reduction method are calculated in detail. The results are: 1) the safety factor obtained from Fellenius's method is smaller than that obtained from Bishop's method; 2) the error between Bishop's method and strength reduction method usually firstly increases and then decrease as the friction angle/cohesive strength becomes larger.
\end{abstract}

\section{Introduction}

The stability analysis of the slope is always the highlight of geotechnical engineering including hydraulic engineering, transportation engineering, tunnel engineering etc. As the developing of the infrastructure, it is very necessary to deal with the slope engineering. The slope can be regarded as a volume with an inclining bottom surface. Under the action of self-weight of the slope and other external actions, there is a sliding tendency from upwards to downwards. If the active downward action surpasses the positive action of resistance, the destruction of the slope occurs.

During the development of the slope research, lots of calculation methods of the safety coefficients have been proposed. In 1916, the Swedish method is proposed by Fellenius and Taylor ${ }^{[1]}$, which is the earliest method for the slope stability analysis. In this method, the sliding surface is supposed to be arc and the positive slide force is on the tangent direction of the weight in the calculation. In 1955, Bishop ${ }^{[2]}$ proposed another simplified method based on the Swedish method in which the arc-shape slide surface and the equilibrium of the moment are kept while the interaction between two strips is considered. Besides, other shapes of the sliding surface instead of the arc surface are also used to compute the safety coefficients such as simplified Janbu method ${ }^{[3]}$. Based on satisfaction of the equilibrium of the moment and the force, Morgenstern and Price ${ }^{[4]}$ proposed a strict deduction of safety analysis assuming arbitrary shape of sliding surface.

Built on the theory of the limit equilibrium method, it is impossible to consider the stress-strain relationship of the soil, the occurrence and development of the slide destroy and the influence of the local deformation on the

\footnotetext{
${ }^{\mathrm{a}}$ Corresponding author: xubinbin@tpei.com.cn
}

stability. Actually, there is close relationship between the stability and the deformation. Before the occurrence of the entire destruction of the slope, significant deformation would also occur. The finite element method can deal with non-linear relationship between stress and strain and calculate the sliding surface without designating the shape in advance. When using the strength reduction method for the stability analysis the cohesive strength and the internal frictional angle are reduced simultaneously. However, the experimental results show that the sensitivity of the internal frictional angle is small and the cohesive strength is large, so it is unreasonable to treat them by the same method.

\section{Calculation model}

There are lots of influence factors of the slope stability, such as the range of computation model, the strength parameters including cohesive strength and inner friction angle. In order to evaluate the effect of strength parameters on the safety factor, a simple slope is used and the sketch is shown in Fig. 1. The gradient of the slope is $1: 2$ and the underground level is below the ground about $20 \mathrm{~m}$. In the slope, the bulk density of the soil is $18 \mathrm{kN} / \mathrm{m}^{3}$ and the soil of the slope is uniform. 


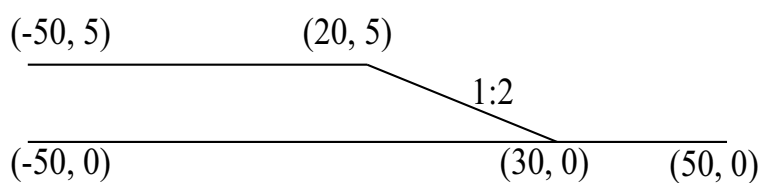

Underground level

$(-50,-20)$

Figure 1. Sketch of the simple slope

The safety factor of the slope is determined by Fellenius's method, Bishop's method and strength reduction method repectively. Two kinds of slope including clay slope and sand slope are evaluted through changing one of the strength parameters while keeping another strength parameters constant. The calculation skeme is listed in Table 1 . There are total 26 cases in the comparison.

Table 1. Calculation skemes

\begin{tabular}{l|c|c|c|c|c|c}
\hline \multicolumn{7}{c}{ Table 1. Calculation skemes } \\
\begin{tabular}{c|c|c|c|c|c|c}
\hline \multicolumn{7}{c}{ clay slope $(c=10 \mathrm{kPa})$ change $\varphi$} \\
\hline 5 & 10 & 15 & 20 & 25 & 30 & 35 \\
\hline 2 & 4 & 6 & 8 & 10 & 12 & 14 \\
\hline \multicolumn{7}{c}{ sand slope $(c=1 \mathrm{kPa})$ change $\varphi$} \\
\hline 15 & 20 & 25 & 30 & 35 & 40 & -- \\
\hline \multicolumn{7}{|c}{ sand slope $(\varphi=30)$ change $c$} \\
\hline 1 & 3 & 5 & 7 & 9 & 11 & -- \\
\hline
\end{tabular}
\end{tabular}

\section{Calculation results}

\subsection{Influence of $\varphi$ for clay slope}

For the clay slope, in order to evaluate the influence of friction angle on the safety factor, the cohesive strength of the soil keeps constant and the friction angle changes from 5 35. Actually a soil with $c=10$ and $\varphi=35$ may not exist in the nature and here it is calculated as a extreme case. The obtained safety factors of clay slope are shown in Table 2. In the table, three safety factors obtained by Fellenius's method, Bishop's method and strength reduction method. The error between Fellenius's method and strength reduction method is marked as E1 and the error between Bishop's method and strength reduction method is marked as E2.

Table 2. Safety factor of clay slope under different $\varphi$

\begin{tabular}{c|c|c|c|c|c|c|c}
\hline & \multicolumn{7}{|c}{ clay slope $(c=10 \mathrm{kPa})$ change $\varphi$} \\
\hline & 5 & 10 & 15 & 20 & 25 & 30 & 35 \\
\hline FM & 1.044 & 1.369 & 1.603 & 1.84 & 2.09 & 2.357 & 2.646 \\
\hline BM & 1.144 & 1.412 & 1.667 & 1.92 & 2.186 & 2.471 & 2.777 \\
\hline SRM & 1.045 & 1.364 & 1.655 & 1.95 & 2.249 & 2.559 & 2.894
\end{tabular}

\begin{tabular}{c|c|c|c|c|c|c|c}
\hline E1\% & 0.1 & -0.37 & 3.24 & 6.03 & 7.61 & 8.57 & 9.37 \\
\hline $\mathrm{E} 2 \%$ & -8.65 & -3.40 & -0.72 & 1.61 & 2.88 & 3.56 & 4.21 \\
\hline
\end{tabular}

p.s. FM, BM and SRM mean Fellenius's method, Bishop's method and strength reduction method; E1 and E2 mean error toward Fellenius's method and Bishop's method.

As can be seen, with increasing friction angle the error between Fellenius's method and strength reduction method increase gradually and the maximum error is as large as $9.37 \%$ when $\varphi=35$. While the the error between Bishop's method and strength reduction method decreases firstly and then increases as the friction angle grows. The maximum error is $8.65 \%$ when $\varphi=35$ and the minimum error is $0.72 \%$ when $\varphi=15$.

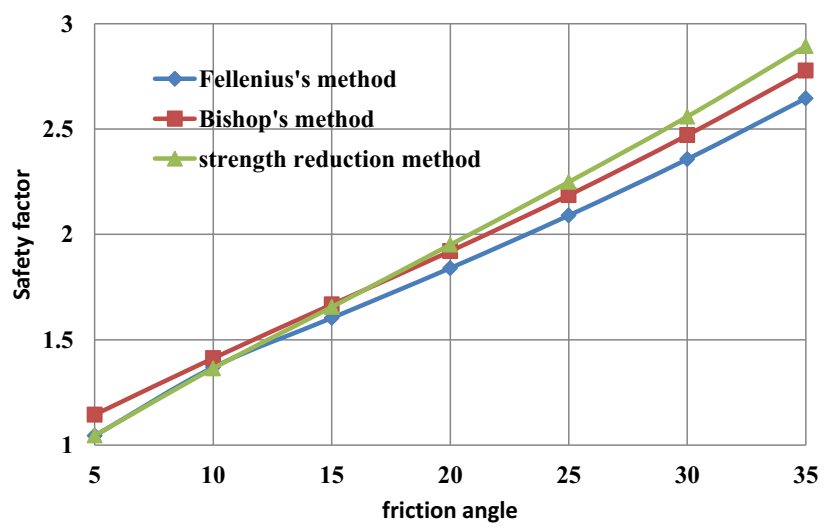

Figure 2. Safety factor v.s. friction angle (clay)

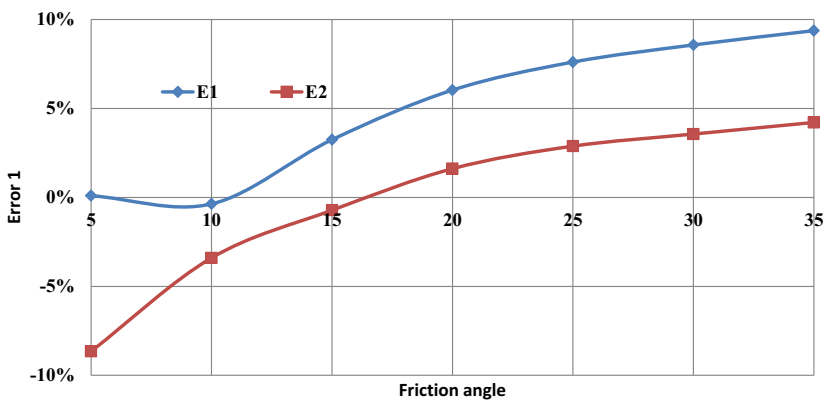

Figure 3. Relative error v.s. friction angle (clay)

The variation of safety factors and relative errors are shown in Figs 2 and 3. As the friction angle increases from 5 to 35 , the safety factor obtained from strength reduction method becomes gradually larger than other two methods. There is a cross point between Bishop's method and strength reduction method.

\subsection{Influence of $c$ for clay slope}

Also for the clay slope, in order to evaluate the influence of cohesive strength on the safety factor, the friction angle of the soil keeps constant and the cohesive strength changes from 2 14. The obtained safety factors of clay slope are shown in Table 3 . In the table, three safety factors obtained by Fellenius's method, Bishop's method and strength reduction method. E1 and E2 have the same meaning. 
Table 3. Safety factor of clay slope under different $c$

\begin{tabular}{c|c|c|c|c|c|c|c}
\hline & \multicolumn{7}{|c}{ clay slope $(\varphi=20 \mathrm{kPa})$ change $c$} \\
\hline & 2 & 4 & 6 & 8 & 10 & 12 & 14 \\
\hline FM & 1.035 & 1.254 & 1.456 & 1.65 & 1.842 & 2.03 & 2.216 \\
\hline BM & 1.084 & 1.318 & 1.526 & 1.73 & 1.92 & 2.11 & 2.303 \\
\hline SRM & 1.137 & 1.38 & 1.584 & 1.77 & 1.951 & 2.11 & 2.282 \\
\hline E1\% & 9.86 & 10.05 & 8.79 & 7.45 & 5.92 & 4.19 & 2.98 \\
\hline E2\% & 4.89 & 4.7 & 3.8 & 2.84 & 1.61 & 0.0 & -0.91 \\
\hline
\end{tabular}

p.s. FM, BM and SRM mean Fellenius's method, Bishop's method and strength reduction method; E1 and E2 mean error toward Fellenius's method and Bishop's method.

As can be seen, when the cohesive strength increases the error between Fellenius's method and strength reduction method decreases gradually with small fluctuiation. The maiximum error is as large as $10.05 \%$ when $c=4 \mathrm{kPa}$. While for the error between Bishop's method and strength reduction method decreases firstly and then increases as the cohesive strength grows. The minimum error is $0.0 \%$ when $c=12 \mathrm{kPa}$ and the maximum error is $4.89 \%$ when $c=2 \mathrm{kPa}$.

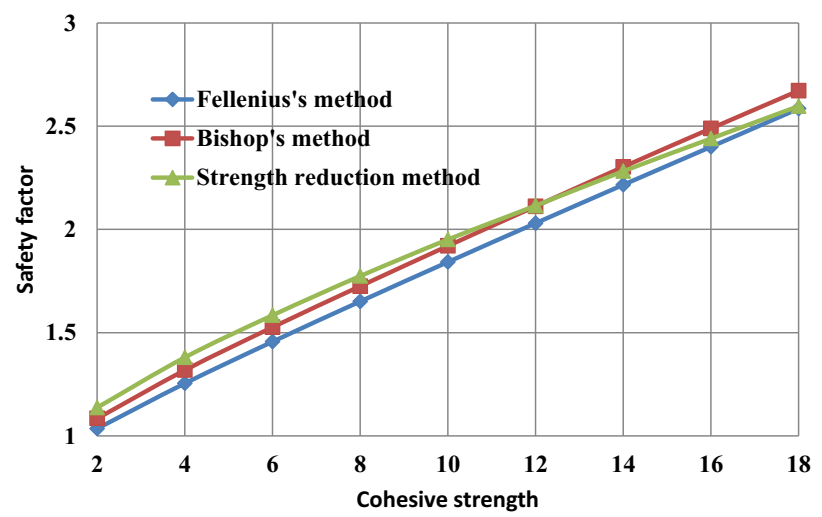

Figure 4. Safety factor v.s. cohesive strength (clay)

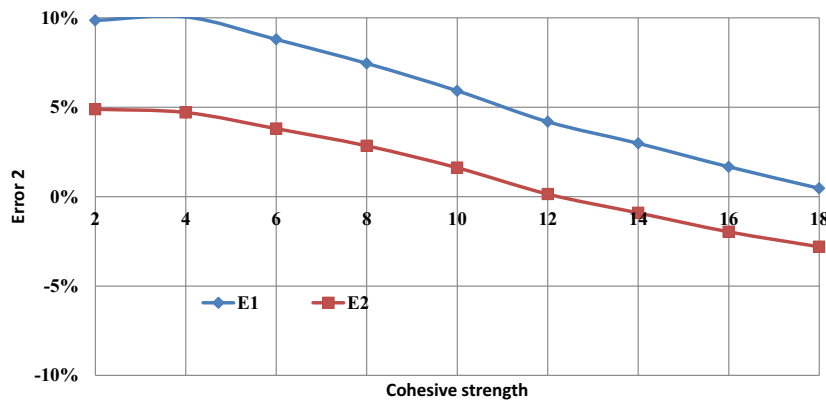

Figure 5. Relative error v.s. cohesive strength (clay)

Figs. 4 and 5 show the variation of safety factors and relative error when the cohesive strength increases. As can be seen, the safety factor obtained from strength reduction method is firstly larger than those obtained from other two methods and then becomes smaller gradually.

\subsection{Influence of $\varphi$ for sand slope}

Similarly, for the sand slope, the influence of friction angle on the safety factor is investigated through changing the friction angle from 15 to 40 . The obtained safety factors of clay slope are shown in Table 4. As the friction angle increases, the error between Fellenius's method and strength reduction method gradually decreases. The maximum and minimum error is $8.85 \%$ and 7.34\% respectively. Also the error between Bishop's method and strength reduction method becomes smaller and the maximum error is $4.24 \%$ when $\varphi=25$.

Table 4. Safety factor of sand slope under different $\varphi$ clay slope $(c=1 \mathrm{kPa})$ change $\varphi$

\begin{tabular}{c|c|c|c|c|c|c}
\hline & 15 & 20 & 25 & 30 & 35 & 40 \\
\hline FM & 0.706 & 0.913 & 1.18 & 1.37 & 1.63 & 1.92 \\
\hline BM & 0.737 & 0.953 & 1.18 & 1.43 & 1.7 & 2.02 \\
\hline SRM & --- & --- & 1.23 & 1.487 & 1.759 & 2.061 \\
\hline E1\% & --- & --- & 8.85 & 8.54 & 7.91 & 7.34 \\
\hline E2\% & --- & --- & 4.24 & 3.99 & 3.47 & 2.03 \\
\hline
\end{tabular}

p.s. FM, BM and SRM mean Fellenius's method, Bishop's method and strength reduction method; E1 and E2 mean error toward Fellenius's method and Bishop's method.

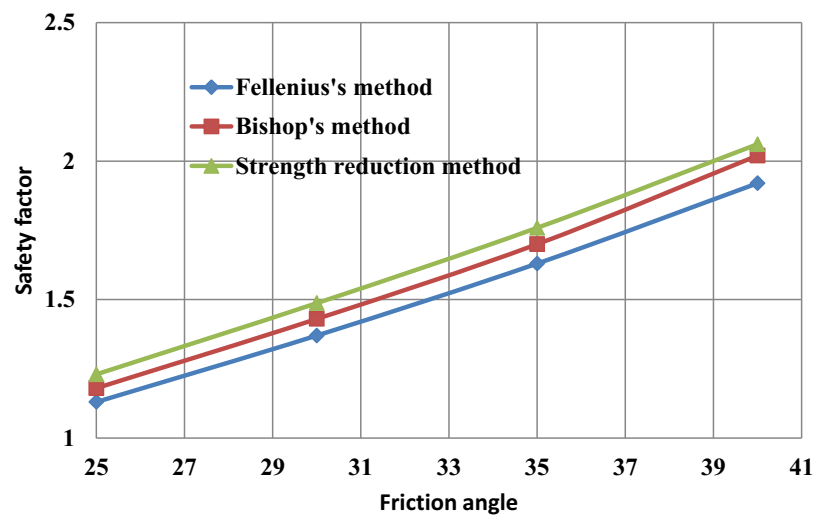

Figure 6. Safety factor v.s. friction angle (sand)

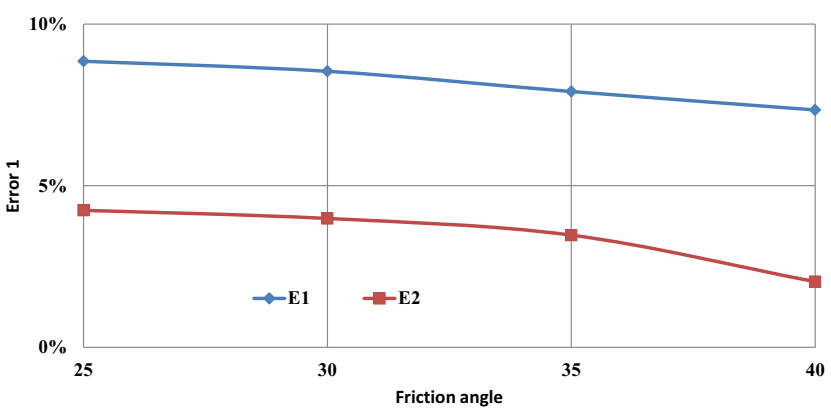

Figure 7. Relative error v.s. friction angle (sand)

Figs. 6 and 7 show the variation of safety factors and relative error when the friction angle increases. As can be seen, the safety factor obtained from strength reduction method is always larger than those obtained from Fellenius's method and Bishop's method.

\subsection{Influence of $c$ for sand slope}

Also for the sand slope, the friction angle of the soil keeps constant and the cohesive strength changes from $1 \sim 11$. The obtained safety factors of sand slope are 
shown in Table 5. In the table, three safety factors obtained by Fellenius's method, Bishop's method and strength reduction method. E1 and E2 have the same meaning.

As can be seen, when the cohesive strength increases the error between Fellenius's method and strength reduction method fluctuiates slightly and the maximum error is as large as $10.19 \%$ when $c=3 \mathrm{kPa}$. While for the error between Bishop's method and strength reduction method increases firstly and then decreases as the cohesive strength grows. The minimum error is $3.43 \%$ when $c=11 \mathrm{kPa}$ and the maximum error is $5.0 \%$ when $c=3 \mathrm{kPa}$.

Table 5. Safety factor of sand slope under different $c$

\begin{tabular}{c|c|c|c|c|c|c}
\hline \multicolumn{7}{c}{ clay slope $(\varphi=30)$ change $c$} \\
\hline & 1 & 3 & 5 & 7 & 9 & 11 \\
\hline FM & 1.367 & 1.62 & 1.847 & 2.056 & 2.26 & 2.454 \\
\hline BM & 1.43 & 1.7 & 1.938 & 2.162 & 2.37 & 2.569 \\
\hline SRM & 1.487 & 1.785 & 2.029 & 2.262 & 2.463 & 2.657 \\
\hline E1\% & 8.78 & 10.19 & 9.85 & 10.02 & 8.98 & 8.27 \\
\hline E2\% & 3.99 & 5.0 & 4.7 & 4.63 & 3.92 & 3.43 \\
\hline
\end{tabular}

p.s. FM, BM and SRM mean Fellenius's method, Bishop's method and strength reduction method; E1 and E2 mean error toward Fellenius's method and Bishop's method.

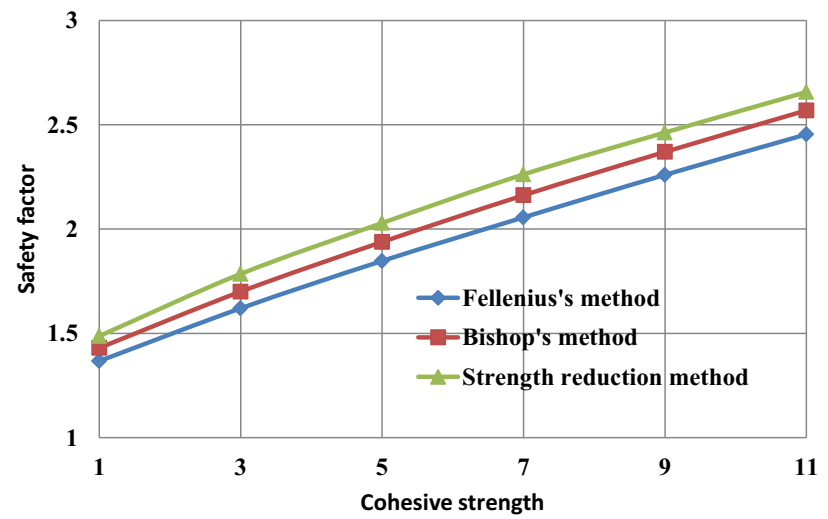

Figure 8. Safety factor v.s. cohesive strength (sand)

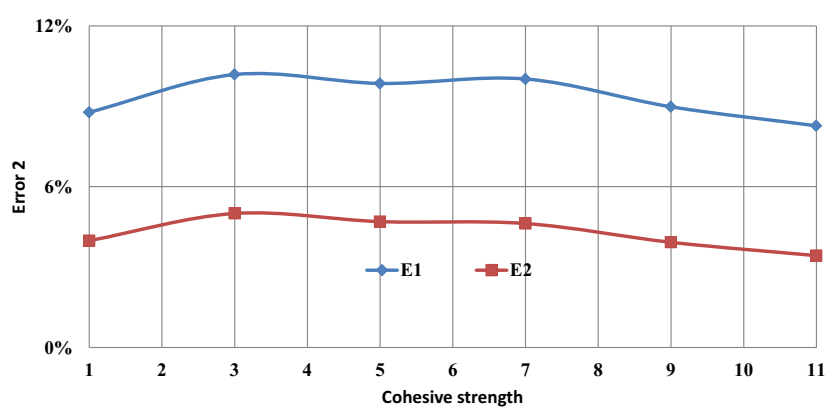

Figure 9. Relative error v.s. cohesive strength (sand)

Figs. 8 and 9 show the variation of safety factors and relative error when the cohesive strength increases. As can be seen, the safety factor obtained from strength reduction method is always larger than those obtained from Fellenius's method and Bishop's method.

\section{Conclusions}

The stability of the slope is influenced by the stiffness of the soil, friction angle, cohesive strength, underground water etc. It is generally believed that the strength parameters of soil including friction angle and cohesive angle have the greatest influence on the safety factor. In this paper, the safety factors uniform clay slope and sand slope are investigated through changing the friction angle and cohesive strength and the conclusions are as follows:

1) With increasing friction angle for the clay slope the error between Fellenius's method and strength reduction method increase gradually and the maximum error is as large as $9.37 \%$. While the the error between Bishop's method and strength reduction method decreases firstly and then increases as the friction angle grows.

2) When the cohesive strength of the clay slope increases the error between Fellenius's method and strength reduction method decreases gradually with small fluctuiation. While for the error between Bishop's method and strength reduction method decreases firstly and then increases as the cohesive strength grows.

3) As the friction angle of the sand slope increases, the error between Fellenius's method and strength reduction method gradually decreases. The maximum and minimum error is $8.85 \%$ and $7.34 \%$ respectively. lso the error between Bishop's method and strength reduction method becomes smaller.

4) When the cohesive strength of the sand slope increases the error between Fellenius's method and strength reduction method fluctuiates slightly and the maximum error is as large as $10.19 \%$ when $c=3 \mathrm{kPa}$. While for the error between Bishop's method and strength reduction method increases firstly and then decreases as the cohesive strength grows.

\section{References}

1. W. Fellinius, Int. Cong. of Large Dams, Washington, 4445 (1936)

2. A.W. Bishop, Geotechnique, 5, 7 (1955)

3. N. Janbu, Proc. of Eur. Conf. on Stability of Earth Slopes, Swenden, 3, 43 (1954)

4. N.R. Morgenstern, Geotechnique, 15, 11 (1965) 